\title{
Mechanisms of Stroke in Patients with Chronic Kidney Disease
}

\author{
Shivani Ghoshal ${ }^{a}$ Barry I. Freedman ${ }^{b}$ \\ ${ }^{a}$ Department of Neurology, Wake Forest School of Medicine, Winston-Salem, NC, USA; ${ }^{b}$ Department of Internal \\ Medicine, Section on Nephrology, Wake Forest School of Medicine, Winston-Salem, NC, USA
}

\begin{abstract}
Keywords
Stroke - Cerebral autoregulation - Cerebral blood flow . Chronic kidney disease $\cdot$ Arteriosclerosis
\end{abstract}

\begin{abstract}
Background: Given the increasing worldwide prevalence of chronic kidney disease (CKD), it is critical to decrease the associated risk of debilitating vascular complications, including stroke, congestive heart failure, myocardial infarction, and peripheral vascular disease. Treatment options for reducing the risk of all subtypes of stroke in patients with CKD remain limited. For patients with end-stage kidney disease (ESKD), novel applications of noninvasive imaging may help personalize the type of dialysis and dialysis prescription for patients at high-risk. Summary: This manuscript reviews the heightened risk of stroke in patients with nephropathy, including ischemic and hemorrhagic subtypes. Mechanisms associated with increased risk include alterations in cardiac output, platelet function, regional cerebral perfusion, accelerated systemic atherosclerosis, altered blood brain barrier, and disordered neurovascular coupling. There is great potential for noninvasive monitoring of the cerebral vasculature using transcranial Doppler (TCD) to reduce stroke risk, particularly in patients with ESKD. Key Messages: Compared to the general population, patients with CKD are at heightened risk for all subtypes of stroke. This is due to a multitude of mechanisms linking nephropathy with altered cerebral perfusion, cerebral neurovascular coupling, and blood ves-
\end{abstract}

\section{KARGER}

(c) 2019 S. Karger AG, Basel

E-Mail karger@karger.com

www.karger.com/ajn sel integrity. Intracranial imaging is not currently standard of care practice in patients with CKD or ESKD. TCD may provide clinicians real-time and noninvasive measurement of brain perfusion. This could be useful for assessing risk of stroke in patients' initiating dialysis, individualizing dialysis prescriptions, and potentially reducing rates of cerebrovascular disease and stroke in high-risk patients. @ 2019 S. Karger AG, Basel

\section{Introduction}

Chronic kidney disease (CKD) is an independent risk factor for stroke, including both hemorrhagic and ischemic subtypes $[1-3,6-8,10]$. Patients with end-stage kidney disease (ESKD) receiving renal replacement therapy are at four-fold to ten-fold higher risk of stroke relative to the general population and stroke risk increases by a factor of seven-fold during the initial year on dialysis [1-4]. Patients with CKD and ESKD also have significantly poorer functional outcomes and greater mortality after suffering a stroke $[1,5]$. It is critical to understand the mechanisms underlying the heightened risk for cerebrovascular accidents in patients with kidney disease.

There are unique influences whereby CKD can impact the risk of stroke. Many factors are involved, including endothelial dysfunction, accelerated arteriosclerosis, and impaired cerebral autoregulation [6,7]. However, stroke prevention measures in patients with CKD remain similar 

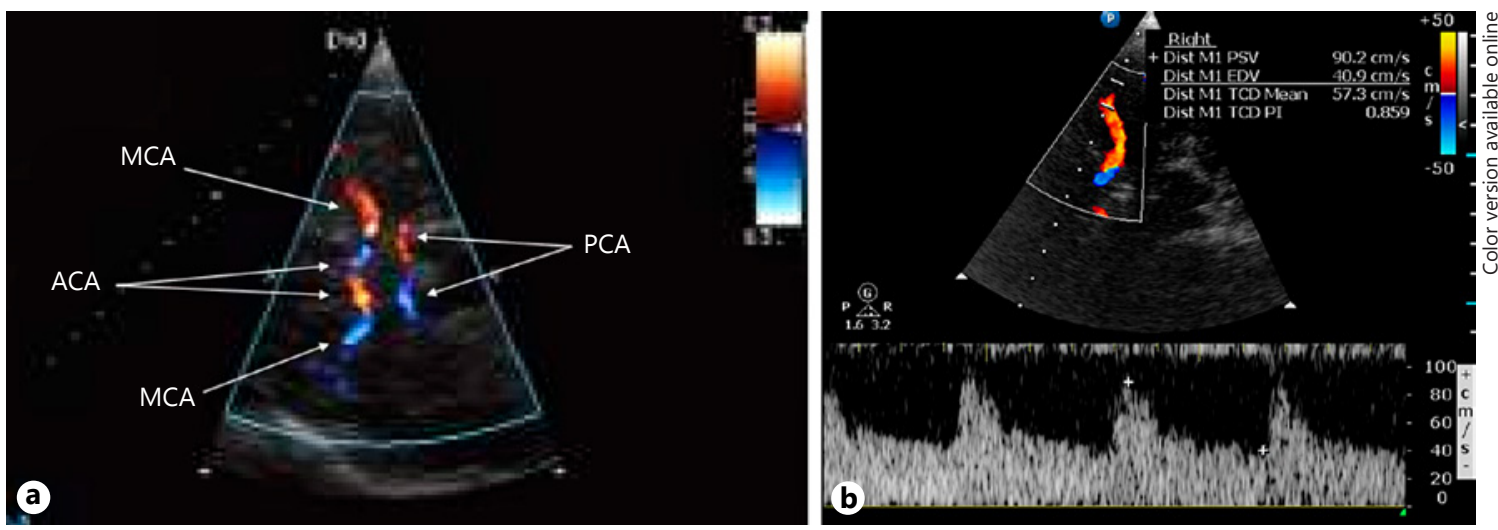

Fig. 1. a TCD transtemporal view of the Circle of Willis, image shows anterior cerebral artery (ACA), middle cerebral artery (MCA), and posterior cerebral artery (PCA) vessels. (b) TCD transtemporal view of the MCA, with a normal waveform.

to those in populations without kidney disease. Thus, there is an unmet need for stroke prevention measures specific to individuals with CKD. Intracranial imaging is not currently standard of care in patients with CKD or ESKD. In patients with ESKD, noninvasive imaging modalities may inform individualized prescriptions for dialysis or choices of dialysis modality (discussed below). Patients at high risk for stroke might be more likely to benefit from dialysis options that reduce the risk of systemic hypotension and exacerbate cerebral hypoperfusion.

This article reviews alterations in cerebral hemodynamics in patients with kidney disease. For patients with ESKD, we discuss the role of dynamic imaging modalities such as transcranial Doppler (TCD) to assess altered cerebral hemodynamics and inform dialysis modalities and prescriptions to minimize the risk of stroke. These sections are accompanied by a brief review of stroke subtypes in patients with CKD and ESKD. This paper is intended to inform nephrologists about disease-specific stroke risk and preventive strategies for their patients.

\section{Epidemiology}

Independent from conventional cardiovascular disease (CVD) risk factors, reductions in estimated glomerular filtration rate (eGFR), and greater degrees of albuminuria increase the risk for stroke. The prospective Atherosclerosis Risk in Communities study reported that $\mathrm{CKD}$, defined as an eGFR $<60 \mathrm{~mL} / \mathrm{min} / 1.73 \mathrm{~m}^{2}$, increased the risk for stroke nearly two-fold (hazard ratio [HR] 1.81, 95\% CI 1.26-2.02), including after adjustment for conventional CVD risk factors [8]. Results were similar to those in the multicenter Prevention Regimen for Effectively Avoiding Second Strokes Trial and a meta-analysis including 284,672 individuals [9, 10]. These reports detected an increased risk of incident stroke among participants with an eGFR $<60 \mathrm{~mL} / \mathrm{min} / 1.73 \mathrm{~m}^{2}$ (relative risk [RR] 1.43; 95\% CI 1.31-1.57) [9, 10]. Effects may be further modulated based on the ancestry of patients. Subgroup analyses in these reports found especially high risks among patients with either an $\mathrm{eGFR}<40 \mathrm{~mL} / \mathrm{min} / 1.73 \mathrm{~m}^{2}$ (RR 1.77, 95\% CI 1.32-2.38) or Asian ancestry (RR 1.96, 95\% CI 1.73-2.23).

Asian and West Africans with kidney disease appear to be at particularly high risk for stroke [11-13]. Large population-based studies support markedly increased stroke risk in Asian ancestry patients with Stage 3 (or higher) CKD. It remains unclear whether inherited (genetic), environmental, or a combination of these factors contribute to risk [12]. In patients with recent African ancestry, renal-risk variants in the apolipoprotein L1 gene (APOL1) may increase risk for kidney disease and stroke [11]. In 25,310 community-based Reasons for Geographic and Racial Differences in Stroke (REGARDS) study participants, higher urine albumin-to-creatinine ratio conferred an increased risk for stroke, particularly among African Americans [13]. A subgroup analysis in REGARDS participants without diabetes mellitus reported that carriage of an APOL1 renal-risk genotype (2 copies of G1 and/or G2 variants) was independently associated with small vessel ischemic stroke [14]. However, it is difficult to determine whether the higher risk for cerebral small vessel disease in REGARDS related to confounding between APOL1-associated kidney disease and the presence of higher blood pressures (e.g., more severe second- 
Table 1. Stroke subtypes and cerebral pathology in patients with kidney disease

\begin{tabular}{llll}
\hline & Effect of CKD & Effect of AKI & References \\
\hline Ischemic stroke & $\uparrow$ & $\uparrow$ & {$[1,5,6,24-36,108,109]$} \\
Hemorrhagic stroke & $\uparrow$ & $\uparrow$ & {$[18-22,110]$} \\
Cerebral microbleeds & $\uparrow$ & Unknown & {$[20,22,111,112]$} \\
SVD & $\uparrow$ & Unknown & {$[39-42,113]$} \\
\hline
\end{tabular}

CKD, chronic kidney disease; AKI, acute kidney injury; SVD, small vessel disease.

Table 2. Mechanisms whereby kidney disease can increase risk of stroke

\begin{tabular}{llll}
\hline Mechanism & Effect of CKD & Effect of AKI & References \\
\hline Cerebral autoregulation & $\downarrow$ & Unknown & {$[57,59]$} \\
Impaired CBF & $\downarrow$ & Unknown & {$[50,55,60,65]$} \\
Rate of carotid atherosclerosis & $\uparrow$ & Unknown & {$[72-75]$} \\
Risk of AF & $\uparrow$ & $\uparrow$ & {$[108,114]$} \\
Uremic platelet dysfunction & $\uparrow$ & $\uparrow$ & {$[1-3,6,115]$} \\
Cerebral oxygenation & $\downarrow$ & $\downarrow$ & {$[67-70,116]$} \\
\hline
\end{tabular}

CKD, chronic kidney disease; AKI, acute kidney injury; CBF, cerebral blood flow; AF, atrial fibrillation.

ary hypertension) related to nephropathy $[15,16]$. No association was detected between APOL1 genotype and incident CVD including stroke, in a meta-analysis with 16,218 African Americans without prevalent CVD [17].

\section{Stroke Subtypes in Patients with Renal Impairment}

Stroke subtypes include ischemic and hemorrhagic variants; each with a different pathogenesis. CKD uniquely affects the risk for hemorrhagic stroke, as well as cardioembolic, large vessel, and small vessel ischemic stroke subtypes $[1-3,6,9]$ (Table 1$)$.

\section{Hemorrhagic Stroke}

CKD increases the risk of intracerebral hemorrhage (ICH) and cerebral microbleeds, defined as small chronic brain hemorrhages that can act as a nidus for future hemorrhagic events [18-23]. Among patients with $\mathrm{ICH}$, an eGFR $<45 \mathrm{~mL} / \mathrm{min} / 1.73 \mathrm{~m}^{2}$ is associated with a three-fold increase in the volume of the hematoma and a four-fold higher risk of death, compared to patients without renal impairment [18]. A retrospective cohort including more than 500,000 participants identified a stepwise association between eGFR and ICH, where the risk of hemorrhage decreased by $9 \%$ ( $95 \%$ CI $8-11 \%$ ) for each $10 \mathrm{~mL} / \mathrm{min} / 1.73$ $\mathrm{m}^{2}$ increase in eGFR, including after adjustment for medical comorbidities, albuminuria, antiplatelet therapy, and use of anticoagulants [23]. Among patients with a recent ICH or ischemic stroke, an eGFR $<60 \mathrm{~mL} / \mathrm{min} / 1.73 \mathrm{~m}^{2}$ was independently associated with the presence and number of cerebral microbleeds, particularly in patients with recent African ancestry [20-22]. In patients on dialysis, ICH is associated with the highest mortality risk of all stroke subtypes [20]. Uremic platelet dysfunction and use of heparin and other anticoagulants during the dialysis procedure may further increase risk of intracranial hemorrhage [21].

\section{Ischemic Stroke}

\section{Cardioembolic}

Compared to the general population, atrial fibrillation (AF) is more than twice as prevalent in patients with CKD and confers a greater risk for thromboembolism [24-31]. The Chronic Renal Insufficiency Cohort reported a prevalence of AF in patients with CKD 2-3 times higher than in the general population [26]. A report from 132,372 patients with nonvalvular AF in the Danish national registry found that patients with predialysis CKD or ESKD had 
Table 3. Noninvasive modalities to image the $\mathrm{CBF}$

\begin{tabular}{|c|c|c|c|}
\hline $\begin{array}{l}\text { Carotid } \\
\text { doppler } \\
\text { ultrasound }\end{array}$ & $\begin{array}{l}\text { Can be done at patient bedside } \\
\text { Well-established guidelines for } \\
\text { application in clinical care } \\
\text { Dynamic study }\end{array}$ & $\begin{array}{l}\text { Does not include intracranial } \\
\text { vessel imaging }\end{array}$ & {$[92,93]$} \\
\hline Perfusion CT & $\begin{array}{l}\text { Well-established guidelines for } \\
\text { ischemia via infarct core and penumbra } \\
\text { Well-established use for application } \\
\text { in clinical care }\end{array}$ & $\begin{array}{l}\text { Contrast administration necessary } \\
\text { Cannot be done at bedside } \\
\text { Not well-established for dynamic } \\
\text { studies }\end{array}$ & {$[118,119]$} \\
\hline $\begin{array}{l}\text { Perfusion } \\
\text { MRI brain }\end{array}$ & $\begin{array}{l}\text { Dynamic study } \\
\text { Detailed spatial resolution of CBF }\end{array}$ & $\begin{array}{l}\text { Contrast administration necessary } \\
\text { Cannot be done at bedside } \\
\text { No well-established guidelines for } \\
\text { application in clinical care }\end{array}$ & {$[120,121]$} \\
\hline
\end{tabular}

CBF, cerebral blood flow; CT, computed tomography; MRI, magnetic resonance imaging; TCD, transcranial doppler.

increased risk of stroke and increased risk of intracranial bleeding relative to those with normal kidney function [25].

\section{Large Vessel}

CKD increases the risk of large vessel stroke via its effects on carotid artery stenosis, plaque size, and carotid intima-media thickness $[1-3,32-36]$. In a series of prospective carotid ultrasound and CT imaging studies of patients after a stroke, those with CKD had significantly higher internal carotid artery stenosis and plaque size, including after adjustment for conventional CVD risk factors [33-35]. CKD was independently associated with carotid atherosclerosis in patients with hypertension [35]. Many patients in these studies were of Asian descent, limiting the generalizability of results; however, the effect of CKD on large vessel and intracranial hemodynamics in other patient populations is an area of active research.

\section{Small Vessel}

The effects of reduced eGFR and increased albuminuria on small vessel ischemic stroke have been intensively studied. Small vessel disease causes $25 \%$ of ischemic strokes $[37,38]$. Reduced eGFR and albuminuria are associated with higher prevalence of small vessel disease [39-42]. The Northern Manhattan Stroke Study showed an eGFR of $15-60 \mathrm{~mL} / \mathrm{min} / 1.73 \mathrm{~m}^{2}$ was associated with a higher volume of white matter hyperintensities after adjusting for conventional CVD risk factors [41]. The Rotterdam Scan Study, which focused on patients 60 years and older, found a similar higher prevalence of white matter lesions after multivariate adjustment (OR 1.11, 95\% CI 0.81-1.51), as well as less deep white matter volume [40]. More recently, a subgroup analysis from the Systolic Blood Pressure Intervention Trial identified increased white matter lesion burden in patients with reduced eGFR $\left(<60 \mathrm{~mL} / \mathrm{min} / 1.73 \mathrm{~m}^{2}\right)$ and high urine albumin-to-creatinine ratio [65].

\section{Stroke Morbidity and Mortality in Patients with CKD}

Kidney disease is associated with a greater neurological deficit following ischemic stroke, a poor functional outcome, and greater mortality [43-49]. In a retrospective study of 3,778 patients with first ischemic stroke, patients with proteinuria had an approximately 1.3-1.7 times higher risk for poor functional outcome, and 3.04.5 times higher risk of in-hospital mortality according to severity of proteinuria. Interestingly, eGFR was not clearly associated with patient clinical outcome in this study [43]. In a large cohort study of Medicare beneficiaries with ischemic stroke, renal dysfunction was independently associated with an increased risk of in-hos- 
pital mortality, with the highest mortality among ischemic stroke patients with eGFR $<15 \mathrm{~mL} / \mathrm{min} / 1.73 \mathrm{~m}^{2}$ (HR 2.09; 95\% CI 1.66-2.63) [45]. Patients on dialysis had an increased risk of 1-year post-stroke rehospitalization (HR 2.04; 95\% CI 1.9-2.18) and 1-year poststroke mortality (HR 2.65; 95\% CI 2.49-2.81) [46, 47]. In an independent longitudinal prospective study among young stroke patients (ages 18-50), an eGFR $<60 \mathrm{~mL} /$ $\mathrm{min} / 1.73 \mathrm{~m}^{2}$ was independently associated with an increased risk of death (HR 4.6; 95\% CI 2.6-8.2) and increased risk of incident stroke (HR 4.1, 95\% CI 1.9-9.0) [48]. However, there were no changes in risk of other vascular events on an average of 11 years after stroke in young patients [48]. Small retrospective studies have found proteinuria is independently associated with poorer discharge functional activity and lower likelihood of being discharged home directly among acute ischemic stroke patients without CKD. In a study of 94 non-CKD patients with recent $\mathrm{ICH}$, the likelihood of being discharged to home were lower in patients with initial proteinuria alone, but this association did not reach statistical significance [49].

\section{Cerebrovascular Hemodynamic Changes in CKD}

Kidney disease has a unique impact on stroke risk by impairing cerebral autoregulation, remodeling the cerebral vasculature, and reducing cerebral blood flow (CBF) [50-54, 57, 59, 60]. Although current research has relied on perfusion magnetic resonance imaging (MRI), TCD ultrasound is an emerging application of noninvasive bedside imaging that holds promise for screening patients with CKD at risk for stroke and is described later in this review (Table 2).

\section{Kidney Disease and Cerebral Autoregulation}

The kidney and brain share similar microvasculature and vasoregulation, leading to shared susceptibility to microvascular dysfunction [54]. Both organs are perfused by "low resistance" vascular circuits, which permit continuous high-volume blood flow during systole and diastole. While small vessels in other organs are protected by upstream vasoconstriction, small arteries in the brain and kidney are constantly exposed to fluctuations in pressure, and flow due to low vascular resistance and upstream vasodilation $[50,54,55,65]$. To maintain relatively constant blood flow to the brain with variable systemic blood pres-

Stroke in Chronic Kidney Disease sures, the brain vasculature displays cerebral autoregulation to minimize hypoperfusion during low blood pressure states and hyperperfusion during high-blood pressure states. Cerebral autoregulation is a complex intrinsic control mechanism that maintains a constant $\mathrm{CBF}$ by changing cerebral vascular resistance in response to changing blood pressure, cerebral perfusion pressure, or metabolic needs. Intact cerebral autoregulation depends on preserved endothelial function and an intact bloodbrain barrier $[56,58]$.

Individuals with a decreased eGFR have less effective cerebral autoregulation. A prospective study of patients after acute ischemic stroke found that poorer autoregulation was correlated with lower eGFR and associated with an increased risk of hemorrhagic transformation of ischemic stroke (OR 6.43; 95\% CI 1.4-32.1) [57]. Hemorrhagic transformation may result from breakthrough hyperperfusion and microvascular injury in the setting of impaired autoregulation. In this study, the combination of reduced eGFR and impaired autoregulation lessened the likelihood of a good functional outcome after stroke (OR 4.39; 95\% CI 3.15-25.6).

In addition to CKD, acute kidney injury (AKI) can impair cerebral autoregulation [61-64]. In renal ischemiareperfusion injury models, AKI caused increased brain microvasculature permeability and damage to the bloodbrain barrier [61, 62, 64]. CKD and AKI are commonly present in patients with posterior reversible encephalopathy syndrome. Posterior reversible encephalopathy syndrome is a result of reduced cerebral autoregulation and endothelial dysfunction that lead to hyperperfusion with protein and fluid extravasation within the parenchyma of the brain $[58,66]$.

\section{The Effects of Kidney Disease on CBF and Oxygenation}

Impaired kidney function can lead to altered $\mathrm{CBF}$ and cerebral oxygen saturation (rSO2) $[65,67-70]$. CBF serves as a measure of cerebrovascular integrity, based on quantitative perfusion of the brain. Patients with impaired cerebral autoregulation are at risk for both hypoperfusion at low levels of systemic blood pressure and hyperperfusion at high levels $[56,58]$. Existing studies on CBF in patients with kidney disease yielded mixed results and questions remain. In a prospective study characterizing regional $\mathrm{CBF}$ based on perfusion MRI in pediatric and young adults with CKD, patients with CKD had higher global CBF and impaired cerebral autoregulation with 
an abnormal direct relationship between systemic blood pressure and white matter CBF [60]. Decreased hematocrit appeared to impact increased global CBF in patients with CKD. The Systolic Blood Pressure Intervention Trial study reported that reduced eGFR was independently associated with higher adjusted median CBF [65]. In contrast, lower eGFR was independently associated with lower CBF in the Rotterdam study; here, each standard deviation reduction in eGFR was associated with a $0.42 \mathrm{~mL} /$ $\mathrm{min} / 100 \mathrm{~mL}$ lower CBF (95\% CI 0.01-0.83) [50]. The high incidence of congestive heart failure in CKD may further impair stroke volume and $\mathrm{CBF}$ and cerebral perfusion $[51,52]$.

In addition to effects on CBF, CKD affects rSO2 [6769]. The majority of this literature focuses on patients with ESKD. In a prospective study, cerebral oxygenation saturation was significantly higher in patients with predialysis CKD than those on dialysis [67]. Multiple regression analysis showed lower cerebral oxygen saturation was independently associated with reduced eGFR. Diabetic patients on hemodialysis had significantly lower rSO2 compared to those without diabetes $(46.8+1.7$ vs. $52.1+1.8 \%, p<0.05)$, and a patient's $\mathrm{rSO} 2$ was affected by blood $\mathrm{pH}$, duration of hemodialysis, and serum albumin concentration [68].

\section{Cerebrovascular Remodeling in CKD}

Creatinine clearance is a strong and independent determinant of arterial stiffness and dilatation in patients with CKD [71-75]. This literature has typically focused on changes in the internal carotid artery and carotid artery intima-medial thickness (cIMT). Briet et al. [72] prospectively evaluated patients with mild to moderate CKD in order to assess the association between arterial stiffness and remodeling as CKD progressed. After 3.5-year follow-up, aortic stiffness was unchanged; however, carotid stiffness increased significantly (adjusted slope, $+0.28+$ $0.05 \mathrm{~m} / \mathrm{s}$ per year, $p<0.0001)$. Estimated GFR was independently related to increased arterial diameter, circumferential wall stress, and carotid artery stiffness. In a multivariate Cox analysis, carotid circumferential wall stress was an independent determinate of progression to ESKD (HR 2.48 [1.63-3.78]. Arterial dilatation results from the inability of a blood vessel's elastic fibers to sustain physiological pulsatile stress $[73,75]$. In the setting of a low resistance organ, such as the brain, this may lead to increased blood flow and strain on the downstream cerebral vasculature $[72,75]$.
cIMT has been studied as a noninvasive predictor of future CVD risk in patients with CKD $[73,74]$. In a prospective longitudinal cohort study, Desbien et al. [73] found that reduced creatinine clearance was significantly associated with faster increases in cIMT. In multivariate analyses, decreased creatinine clearance (HR 1.04, 95\% CI 1.02-1.23) and faster increases in cIMT (HR 1.15, 95\% CI 1.11-1.93) were associated with fatal and nonfatal vascular events. Another prospective study by Kastarinen et al. [74] found that even minor reductions in eGFR were independently associated with increased cIMT, particularly among middle-aged men and post-menopausal women. These studies suggest that subclinical atherosclerosis is impacted by kidney function, and the addition of cIMT may improve noninvasive risk stratification in those with early-stage CKD.

\section{Special Considerations for Stroke Risk in ESKD}

Patients with ESKD on dialysis are at higher risk of stroke, with rates varying from 10 to 33 per 1,000 patientyears [4, 76-84]. African American men with ESKD are at particular risk compared to the general population, with an age-adjusted RR of stroke of 9.7 (95\% CI 8.211.2), compared to European American men (RR 6.1, CI 5.1-7.1) [76]. A retrospective 7-year study from Power et al. [77] reported that first stroke occurred at a rate of 14.9/1000 patient-years in those with ESKD (95\% CI 12.2-17.9). Although there was a predominance of ischemic (versus hemorrhagic subtype) strokes, patients of South Asian ethnicity were more prone to hemorrhagic strokes.

Initiation of dialysis per se is associated with a heightened risk of stroke, well above the general increased risk seen in prevalent patients with ESKD $[4,78,79,82]$. In a 22 -year single-center retrospective study, $39 \%$ of ischemic and 35\% of hemorrhagic strokes occurred during or shortly after a hemodialysis session [80].

A population-based study of elderly U.S. dialysis patients reported that irrespective of the dialysis modality, stroke rates begin to rise approximately 3 months prior to the initiation of renal replacement therapy and peaked during the first 30 days after dialysis initiation [4]. In a Taiwanese study, Wang et al. [79] observed that patients on hemodialysis and peritoneal dialysis had similarly high HRs for ischemic stroke (2.88 for hemodialysis, 3.21 for peritoneal dialysis) and hemorrhagic stroke (6.83 for hemodialysis, 6.15 for peritoneal dialysis), a finding reproduced by other investigators $[82,83]$. 
Polinder-Bos et al. [70] studied the acute effects of conventional hemodialysis on $\mathrm{CBF}$ and found that the hemodialysis session had significant, though largely asymptomatic, declines in global CBF. The long-term effects of repeated episodes of reduced CBF on cognitive performance remain to be determined.

\section{Intracranial Imaging in Kidney Disease}

Intracranial imaging is not currently a standard of care practice prior to dialysis initiation. Patients are not routinely screened for carotid stenosis or intracranial stenosis and their cerebral autoregulatory capacity is not assessed. Taking preexisting intracranial pathology in these patients into account may better inform selection of dialysis modality, individualize prescriptions, ultrafiltration goals, and intradialytic blood pressure goals to minimize stroke risk. For nondialysis CKD patients, imaging may help assess for overall stroke risk and progression.

Practical cranial vascular imaging options for patients with kidney disease include carotid duplex ultrasonography, computed tomography angiography (CTA), magnetic resonance imaging angiography (MRA), and TCD ultrasonography. Of these options, carotid duplex ultrasonography is appealing as a cost-effective, dynamic, noninvasive bedside modality to measure carotid plaque and stenosis, though it is limited by its inability to assess intracranial circulation [84]. CTA and MRA are useful modalities to assess morphology of intracranial vessels, though they are static studies and cannot relay flow dynamics or cerebral autoregulatory capacity. CTA is further limited by its dependence on IV contrast. MRA may be completed with or without contrast. Perfusion MRI and perfusion computed tomography of the head are less practical in CKD populations, in part due to necessity of contrast administration. TCD, an established imaging technique, may be a practical, informative tool to assess intracranial hemodynamics in CKD (Table 3).

\section{Role of TCD Ultrasound in Kidney Disease}

TCD ultrasonography is a useful bedside tool used for repeated, noninvasive monitoring of cerebrovascular hemodynamics as a marker for CBF, resistance to flow, and vessel autoregulation (Fig. 1). Common TCD variables include a cerebral vessel's peak systolic velocity, mean flow velocity (MFV), and Gosling pulsatility index (PI). PI measures the variability of blood velocity in a vessel and describes distal cerebrovascular resistance. The TCD waveform itself shows a low resistance pattern characteristic of cerebral hemodynamics, with a sharp systolic upstroke and slow decay. Cerebrovascular autoregulation is measured by increased MFV and decreased PI with increased arterial carbon dioxide as the vessel vasodilates. In impaired cerebral autoregulation, MFV and PI do not respond to changes in carbon dioxide $[90,98]$.

TCD waveform analysis, combined with trends in MFV and PI, serves as useful noninvasive bedside markers for changes in CBF. TCD is an emerging tool in dialysis medicine, although studies have largely focused on monitoring declines in MFV during hemodialysis [8589, 91, 94, 95]. An observational study of MFV fluctuations in patients receiving chronic maintenance hemodialysis found significant reductions in the middle cerebral and basilar arteries through the procedure. Amount of fluid removed and change in hematocrit significantly correlated with change in MFV [86]. Separate studies corroborated with similar MCA MFV drops during hemodialysis, which inversely correlated to ultrafiltration volume $[87,95]$. In contrast, a small study found no significant intradialytic changes in MFV even with significant changes in mean arterial pressure [88]. Dynamic cerebral autoregulation and carbon dioxide reactivity remained normal in patients with chronic renal failure and were not significantly altered by hemodialysis, though this observation is limited by small study population [89].

Changes in MFV and other TCD metrics have significant clinical impact. In a recent prospective observational study of 97 patients receiving chronic hemodialysis, patients showed significant intradialytic decline in MFV. Percentage decline in MFV correlated significantly with MRI white matter disease burden as well as poor executive function on cognitive testing [91]. Serial TCD may be helpful in assessing progression of known white matter disease burden in patients with CKD, as TCD and MRI studies have found strong correlation between TCD PI and white matter disease severity [92-94].

TCD may help identify dialysis-dependent patients at particular risk of hypoperfusion or cerebral ischemia and personalize dialysis prescription. For patients with ESKD who are initiating dialysis, detection of intracranial stenoses and altered cerebral autoregulation may assist in selecting the appropriate dialysis modality, goal intradialytic blood pressures, and length of treatment sessions [96]. An observational study found significant intradialytic MFV decreases in a subset of chronic hemodialysis patients, but especially marked drops in patients with concomitant carotid stenosis on study ultrasound [87]. Chronicity of di- 
alysis dependence may also be a significant factor in intradialytic cerebral hemodynamics. A prospective study compared intradialytic MFV changes in critically ill patients with AKI compared to patients with ESKD. Significant MFV decreases among those with AKI, but not ESKD [85].

Real-time TCD results are an exciting addition to the field. They may provide significant benefits, but there are also important limitations. TCD has the potential for continuous noninvasive monitoring of cerebral perfusion during dialysis, as well as serial longitudinal measurements to assess white matter disease burden and guide changes in individualized dialysis prescription over time.

Nephrologists can modify selection of renal-replacement modalities in patients at high risk of stroke or cognitive decline. A prospective study found that cognitive function declined faster with hemodialysis compared with peritoneal dialysis, despite similar baseline cognitive scores and adjustment for education and demographics [97]. Peritoneal dialysis, particularly nocturnal supine treatments, may be attractive in patients with the requisite skill set and a supportive home environment. Additional alterations to treatment that nephrologists can employ to preserve cerebral perfusion and reduce systemic hyportension include use of midodrine hydrochloride (an a1-receptor agonist), more frequent in-center hemodialysis (4 treatments per week), home hemodialysis (5 treatments per week), extending treatment durations during hemodialysis, or instituting weight-based ultrafiltration limits [99]. Real-time TCD can be applied with different renal replacement modalities and prescriptions to optimize therapy. However, TCD measurements may be limited on operator experience as well as patient anatomy [100-102]. An estimated 8-9\% of patients do not have an appropriate transtemporal or occipital acoustic window for vessel insonation due to skull thickness [102]. Despite these limitations, the use of TCD has expanded with improved technology and improved access to formal TCD training programs $[91,103]$.

\section{Unmet Needs and Future Directions}

The prevalence of CKD and ESKD is increasing, as is the risk of stroke. Effective noninvasive screening and primary prevention tools are urgently needed to minimize stroke-related morbidity and mortality in this population. At present, there are no primary stroke prevention measures that are specific for patients with CKD, nor are there measures for screening patients at particularly high risk. Studies employing renin-angiotensin system modulators in patients with CKD did not identify reductions in the short-term risk of stroke $[104,106]$. The potential benefit of reducing albuminuria to lower the risk of stroke in patients with CKD is also unclear [3].

Research regarding the effects of arterial remodeling and altered autoregulation in patients with moderate reductions in eGFR is ongoing. In patients with reduced cerebral autoregulation or intracranial stenosis due to accelerated atherosclerosis, a lower blood pressure target may paradoxically worsen the risk of hypoperfusion and ischemic stroke $[104,105]$. TCD may prove beneficial in setting patient-specific blood pressure goals and identifying patients at particularly high risk of stroke. Thus, TCD may soon change our approach to choosing dialysis modalities and delivering dialysis in patients with underlying CVD and cerebrovascular disease, particularly during the initial period of dialysis initiation and when changing therapies. TCD provides an exciting potential advance in stroke prevention in patients with advanced kidney disease.

\section{Disclosure Statement}

The authors have no conflicts of interest to disclose.

\section{Grant Support}

None.

\section{References}

1 Dad T, Weiner DE. Stroke and chronic kidney disease: epidemiology, pathogenesis, and management across kidney disease stages. Semin Nephrol. 2015 Jul;35(4):311-22.

2 Toyoda K, Ninomiya T. Stroke and cerebrovascular diseases in patients with chronic kidney disease. Lancet Neurol. 2014 Aug;13(8): 823-33.

3 Arnold J, Sims D, Ferro CJ. Modulation of stroke risk in chronic kidney disease. Clin Kidney J. 2016 Feb;9(1):29-38.
4 Murray AM, Seliger S, Lakshminarayan K, Herzog CA, Solid CA. Incidence of stroke before and after dialysis initiation in older patients. J Am Soc Nephrol. 2013 Jun;24(7):1166-73.

5 Yahalom G, Schwartz R, Schwammenthal Y, Merzeliak O, Toashi M, Orion D, et al. Chronic kidney disease and clinical outcome in patients with acute stroke. Stroke. 2009 Apr; 40(4):1296-303.

6 Arnold R, Issar T, Krishnan AV, Pussell BA. Neurological complications in chronic kid- ney disease. JRSM Cardiovasc Dis. 2016 Nov 3;5:2048004016677687.

7 Krishnan AV, Kiernan MC. Neurological complications of chronic kidney disease. Nat Rev Neurol. 2009 Oct;5(10):542-51.

8 Abramson JL, Jurkovitz CT, Vaccarino V, Weintraub WS, McClellan W. Chronic kidney disease, anemia, and incident stroke in a middle-aged, community-based population: the ARIC Study. Kidney Int. 2003 Aug;64(2): 610-5. 
9 Lee M, Saver JL, Chang KH, Liao HW, Chang SC, Ovbiagele B. Low glomerular filtration rate and risk of stroke: meta-analysis. BMJ. 2010 Sep 30;341:c4249.

10 Ovbiagele B, Bath PM, Cotton D, Sha N, Diener HC; PRoFESS Investigators. Low glomerular filtration rate, recurrent stroke risk, and effect of renin-angiotensin system modulation. Stroke. 2013 Nov;44(11): 3223-5.

11 Sarfo FS, Mobula LM, Sarfo-Kantanka O, Adamu S, Plange-Rhule J, Ansong D, et al. Estimated glomerular filtration rate predicts incident stroke among Ghanaians with diabetes and hypertension. J Neurol Sci. 2019 Jan;396: $140-7$.

12 Gutiérrez OM, Judd SE, Muntner P, Rizk DV, McClellan WM, Safford MM, et al. Racial differences in albuminuria, kidney function, and risk of stroke. Neurology. 2012 Oct;79(16): 1686-92.

13 Muntner P, Judd SE, McClellan W, Meschia JF, Warnock DG, Howard VJ. Incidence of stroke symptoms among adults with chronic kidney disease: results from the REasons for Geographic And Racial Differences in Stroke (REGARDS) study. Nephrol Dial Transplant. 2012 Jan;27(1):166-73.

14 Gutiérrez OM, Irvin MR, Chaudhary NS, Cushman M, Zakai NA, David VA, et al. APOL1 Nephropathy Risk Variants and Incident Cardiovascular Disease Events in Community-Dwelling Black Adults. Circ Genom Precis Med. 2018 Jun;11(6):e002098.

15 Akinyemi R, Tiwari HK, Arnett DK, Ovbiagele $B$, Irvin MR, Wahab K, et al.; SIREN Investigators. APOL1, CDKN2A/CDKN2B, and HDAC9 polymorphisms and small vessel ischemic stroke. Acta Neurol Scand. 2018 Jan; 137(1):133-41.

16 Ito $\mathrm{K}$, Bick AG, Flannick J, Friedman DJ, Genovese G, Parfenov MG, et al. Increased burden of cardiovascular disease in carriers of APOL1 genetic variants. Circ Res. 2014 Feb; 114(5):845-50.

17 Grams ME, Surapaneni A, Ballew SH, Appel LJ, Boerwinkle E, Boulware LE, et al. APOL1 kidney risk variants and cardiovascular disease: an individual participant data metaanalysis. J Am Soc Nephrol. 2019, DOI: 10.1681/ASN.2019030240.

18 Molshatzki N, Orion D, Tsabari R, Schwammenthal Y, Merzeliak O, Toashi M, et al. Chronic kidney disease in patients with acute intracerebral hemorrhage: association with large hematoma volume and poor outcome. Cerebrovasc Dis. 2011;31(3):271-7.

19 Lee JG, Lee KB, Jang IM, Roh H, Ahn MY, Woo HY, et al. Low glomerular filtration rate increases hemorrhagic transformation in acute ischemic stroke. Cerebrovasc Dis. 2013; 35(1):53-9.

20 Ryu WS, Lee SH, Kim CK, Kim BJ, Yoon BW. The relation between chronic kidney disease and cerebral microbleeds: difference between patients with and without diabetes. Int J Stroke. 2012 Oct;7(7):551-7.
21 Wakasugi M, Matsuo K, Kazama JJ, Narita I. Higher mortality due to intracerebral hemorrhage in dialysis patients: a comparison with the general population in Japan. Ther Apher Dial. 2015 Feb;19(1):45-9.

22 Ovbiagele B, Wing JJ, Menon RS, Burgess RE Gibbons MC, Sobotka I, et al. Association of chronic kidney disease with cerebral microbleeds in patients with primary intracerebral hemorrhage. Stroke. 2013 Sep;44(9):2409-13.

23 Molnar AO, Bota SE, Garg AX, Harel Z, Lam $\mathrm{N}$, McArthur E, et al. The risk of major hemorrhage with CKD. J Am Soc Nephrol. 2016 Sep;27(9):2825-32.

24 Wetmore JB, Ellerbeck EF, Mahnken JD, Phadnis M, Rigler SK, Mukhopadhyay P, et al. Atrial fibrillation and risk of stroke in dialysis patients. Ann Epidemiol. 2013 Mar;23(3): 112-8.

25 Zimmerman D, Sood MM, Rigatto C, Holden RM, Hiremath S, Clase CM. Systematic review and meta-analysis of incidence, prevalence and outcomes of atrial fibrillation in patients on dialysis. Nephrol Dial Transplant. 2012 Oct;27(10):3816-22.

26 Soliman EZ, Prineas RJ, Go AS, Xie D, Lash JP, Rahman M, et al.; Chronic Renal Insufficiency Cohort (CRIC) Study Group. Chronic kidney disease and prevalent atrial fibrillation: the Chronic Renal Insufficiency Cohort (CRIC). Am Heart J. 2010 Jun;159(6):1102-7.

27 Hart RG, Pearce LA, Asinger RW, Herzog CA. Warfarin in atrial fibrillation patients with moderate chronic kidney disease. Clin J Am Soc Nephrol. 2011 Nov;6(11):2599-604.

28 Reinecke H, Engelbertz C, Schäbitz WR. Preventing stroke in patients with chronic kidney disease and atrial fibrillation: benefit and risks of old and new oral anticoagulants. Stroke. 2013 Oct;44(10):2935-41.

29 Hohnloser SH, Hijazi Z, Thomas L, Alexander JH, Amerena J, Hanna M, et al. Efficacy of apixaban when compared with warfarin in relation to renal function in patients with atrial fibrillation: insights from the ARISTOTLE trial. Eur Heart J. 2012 Nov;33(22): 2821-30.

30 Connolly SJ, Ezekowitz MD, Yusuf S, Eikelboom J, Oldgren J, Parekh A, et al.; RE-LY Steering Committee and Investigators. Dabigatran versus warfarin in patients with atrial fibrillation. N Engl J Med. 2009 Sep;361(12): 1139-51.

31 Piccini JP, Stevens SR, Chang Y, Singer DE, Lokhnygina $\mathrm{Y}$, Go AS, et al.; ROCKET AF Steering Committee and Investigators. Renal dysfunction as a predictor of stroke and systemic embolism in patients with nonvalvular atrial fibrillation: validation of the $\mathrm{R}(2)$ CHADS(2) index in the ROCKET AF (Rivaroxaban Once-daily, oral, direct factor $\mathrm{Xa}$ inhibition Compared with vitamin $\mathrm{K}$ antagonism for prevention of stroke and Embolism Trial in Atrial Fibrillation) and ATRIA (AnTicoagulation and Risk factors In Atrial fibrillation) study cohorts. Circulation. 2013 Jan; 127(2):224-32.
32 Marulanda-Londoño E, Chaturvedi S. Stroke due to large vessel atherosclerosis: five new things. Neurol Clin Pract. 2016 Jun;6(3):2528.

33 Kajitani N, Uchida HA, Suminoe I, Kakio Y, Kitagawa M, Sato H, et al. Chronic kidney disease is associated with carotid atherosclerosis and symptomatic ischaemic stroke. J Int Med Res. 2018 Sep;46(9):3873-83.

$34 \mathrm{Yu}$ FP, Zhao YC, Gu B, Hu J, Yang YY. Chronic kidney disease and carotid atherosclerosis in patients with acute stroke. Neurologist. 2015 Aug;20(2):23-6.

35 Ohara T, Kokubo Y, Toyoda K, Watanabe M, Koga M, Nakamura S, et al. Impact of chronic kidney disease on carotid atherosclerosis according to blood pressure category: the Suita study. Stroke. 2013 Dec;44(12):3537-9.

36 Kokubo Y. Carotid atherosclerosis in kidney disease. Contrib Nephrol. 2013;179:35-41.

37 Warlow C, Sudlow C, Dennis M, Wardlaw J, Sandercock P. Stroke. Lancet. 2003 Oct; 362(9391):1211-24.

38 Pantoni L. Cerebral small vessel disease: from pathogenesis and clinical characteristics to therapeutic challenges. Lancet Neurol. 2010 Jul;9(7):689-701.

39 Toyoda K. Cerebral small vessel disease and chronic kidney disease. J Stroke. 2015 Jan; 17(1):31-7.

40 Ikram MA, Vernooij MW, Hofman A, Niessen WJ, van der Lugt A, Breteler MM. Kidney function is related to cerebral small vessel disease. Stroke. 2008 Jan;39(1):55-61.

41 Khatri M, Wright CB, Nickolas TL, Yoshita M, Paik MC, Kranwinkel G, et al. Chronic kidney disease is associated with white matter hyperintensity volume: the Northern Manhattan Study (NOMAS). Stroke. 2007 Dec; 38(12):3121-6.

42 Tsai YH, Lee M, Lin LC, Chang SW, Weng $\mathrm{HH}$, Yang JT, et al. Association of chronic kidney disease with small vessel disease in patients with hypertensive intracerebral hemorrhage. Front Neurol. 2018 May;9:284.

43 Ovbiagele B, Sanossian N, Liebeskind DS, Kim D, Ali LK, Pineda S, et al. Indices of kidney dysfunction and discharge outcomes in hospitalized stroke patients without known renal disease. Cerebrovasc Dis. 2009;28(6): 582-8.

44 Kumai Y, Kamouchi M, Hata J, Ago T, Kitayama J, Nakane $\mathrm{H}$, et al.; FSR Investigators. Proteinuria and clinical outcomes after ischemic stroke. Neurology. 2012 Jun;78(24): 1909-15.

45 El Husseini N, Fonarow GC, Smith EE, Ju C Schwamm LH, Hernandez AF, et al. Renal Dysfunction Is Associated With Poststroke Discharge Disposition and In-Hospital Mortality: Findings From Get With The Guidelines-Stroke. Stroke. 2017 Feb;48(2):327-34.

46 El Husseini N, Fonarow GC, Smith EE, Ju C, Sheng S, Schwamm LH, et al. Association of kidney function with 30-day and 1-year poststroke mortality and hospital readmission. Stroke. 2018 Dec;49(12):2896-903. 
47 Alqahtani F, Berzingi CO, Aljohani S, Al Hajji M, Diab A, Alvi M, et al. Temporal trends in the outcomes of dialysis patients admitted with acute ischemic stroke. J Am Heart Assoc. 2018 Jun;7(12):e008686.

48 Synhaeve NE, van Alebeek ME, Arntz RM, Maaijwee NA, Rutten-Jacobs LC, Schoonderwaldt $\mathrm{HC}$, et al. Kidney dysfunction increases mortality and incident events after young stroke: the FUTURE study. Cerebrovasc Dis. 2016;42(3-4):224-31.

49 Ovbiagele B, Pineda S, Saver JL. Renal dysfunction and discharge destination in patients with intracerebral hemorrhage. J Stroke Cerebrovasc Dis. 2011 Mar-Apr;20(2):145-9.

50 Sedaghat S, Vernooij MW, Loehrer E, Mattace-Raso FU, Hofman A, van der Lugt A, et al. Kidney function and cerebral blood flow: the Rotterdam study. J Am Soc Nephrol. 2016 Mar;27(3):715-21.

51 Kottgen A, Russell SD, Loehr LR, Crainiceanu $\mathrm{CM}$, Rosamond WD, Chang PP, et al. Reduced kidney function as a risk factor for incident heart failure: the atherosclerosis risk in communities (ARIC) study. I Am Soc Nephrol. 2007 Apr;18(4):1307-15.

52 Gruhn N, Larsen FS, Boesgaard S, Knudsen GM, Mortensen SA, Thomsen G, et al. Cerebral blood flow in patients with chronic heart failure before and after heart transplantation. Stroke. 2001 Nov;32(11):2530-3

53 Lavi S, Gaitini D, Milloul V, Jacob G. Impaired cerebral $\mathrm{CO} 2$ vasoreactivity: association with endothelial dysfunction. Am J Physiol Heart Circ Physiol. 2006 Oct 291(4):H1856-61.

54 Schiller A, Covic A. Kidney and brain-a renal perspective of 'Les Liaisons Dangereuses'. Nephrol Dial Transplant. 2010 May;25(5) 1370-3.

55 Pierro ML, Kainerstorfer JM, Civiletto A, Weiner DE, Sassaroli A, Hallacoglu B, et al. Reduced speed of microvascular blood flow in hemodialysis patients versus healthy controls: a coherent hemodynamics spectroscopy study. J Biomed Opt. 2014 Feb;19(2):026005.

56 Thompson CS, Hakim AM. Living beyond our physiological means: small vessel disease of the brain is an expression of a systemic failure in arteriolar function: a unifying hypothesis. Stroke. 2009 May;40(5):e322-30.

57 Castro P, Azevedo E, Rocha I, Sorond F, Serrador JM. Chronic kidney disease and poor outcomes in ischemic stroke: is impaired cerebral autoregulation the missing link? BMC Neurol. 2018 Mar;18(1):21.

58 Armstead WM. Cerebral blood flow autoregulation and dysautoregulation. Anesthesiol Clin. 2016 Sep;34(3):465-77.

59 Carlström M, Wilcox CS, Arendshorst WJ. Renal autoregulation in health and disease. Physiol Rev. 2015 Apr;95(2):405-511.

60 Liu HS, Hartung EA, Jawad AF, Ware JB, Laney N, Port AM, et al. Regional cerebral blood flow in children and young adults with chronic kidney disease. Radiology. 2018 Sep; 288(3):849-58
61 Malek M. Brain consequences of acute kidney injury: focusing on the hippocampus. Kidney Res Clin Pract. 2018 Dec;37(4):315-22.

62 Liu M, Liang Y, Chigurupati S, Lathia JD, Pletnikov M, Sun Z, et al. Acute kidney injury leads to inflammation and functional changes in the brain. J Am Soc Nephrol. 2008 Jul; 19(7):1360-70.

63 Fleegal-DeMotta MA, Doghu S, Banks WA. Angiotensin II modulates BBB permeability via activation of the $\mathrm{AT}(1)$ receptor in brain endothelial cells. J Cereb Blood Flow Metab. 2009 Mar;29(3):640-7.

64 Biancardi VC, Stern JE. Compromised blood-brain barrier permeability: novel mechanism by which circulating angiotensin II signals to sympathoexcitatory centres during hypertension. J Physiol. 2016 Mar; 594(6):1591-600.

65 Tamura MK, Pajewski NM, Bryan RN, Weiner DE, Diamond M, Van Buren P, et al. SPRINT Study Research Group. Chronic kidney disease, cerebral blood flow, and white matter volume in hypertensive adults. Neurology. 2016 Mar;86(13):1208-16.

66 Fugate JE, Claassen DO, Cloft HJ, Kallmes DF, Kozak OS, Rabinstein AA. Posterior reversible encephalopathy syndrome: associated clinical and radiologic findings. Mayo Clin Proc. 2010 May;85(5):427-32.

67 Miyazawa $\mathrm{H}$, Ookawara S, Ito K, Ueda Y, Yanai K, Ishii $\mathrm{H}$, et al. Association of cerebral oxygenation with estimated glomerular filtration rate and cognitive function in chronic kidney disease patients without dialysis therapy. PLoS One. 2018 Jun;13(6): e0199366.

68 Ito K, Ookawara S, Ueda Y, Goto S, Miyazawa $\mathrm{H}$, Yamada $\mathrm{H}$, et al. Factors affecting cerebral oxygenation in hemodialysis patients: cerebral oxygenation associates with $\mathrm{pH}$, hemodialysis duration, serum albumin concentration, and diabetes mellitus. PLoS One. 2015 Feb;10(2):e0117474.

69 Papadopoulos G, Dounousi E, Papathanasiou A, Papathanakos G, Tzimas P. Cerebral oximetry values in dialyzed surgical patients: a comparison between hemodialysis and peritoneal dialysis. Ren Fail. 2013 Jul;35(6):855-9.

70 Polinder-Bos HA, García DV, Kuipers J, Elting JW, Aries MJ, Krijnen WP, et al. Hemodialysis induces an acute decline in cerebral blood flow in elderly patients. J Am Soc Nephrol. 2018 Apr;29(4):1317-25.

71 Bugnicourt JM, Chillon JM, Massy ZA, Canaple S, Lamy C, Deramond H, et al. High prevalence of intracranial artery calcification in stroke patients with CKD: a retrospective study. Clin J Am Soc Nephrol. 2009 Feb;4(2): 284-90.

72 Briet M, Bozec E, Laurent S, Fassot C, London GM, Jacquot C, et al. Arterial stiffness and enlargement in mild-to-moderate chronic kidney disease. Kidney Int. 2006 Jan;69(2):350-

73 Desbien AM, Chonchol M, Gnahn H, Sander D. Kidney function and progression of carot- id intima-media thickness in a community study. Am J Kidney Dis. 2008 Apr;51(4):58493.

74 Kastarinen H, Ukkola O, Kesäniemi YA. Glomerular filtration rate is related to carotid intima-media thickness in middle-aged adults. Nephrol Dial Transplant. 2009 Sep;24(9): 2767-72.

75 O'Rourke MF, Safar ME. Relationship between aortic stiffening and microvascular disease in brain and kidney: cause and logic of therapy. Hypertension. 2005 Jul;46(1):200-4.

76 Nayak-Rao S, Shenoy MP. Stroke in Patients with Chronic Kidney Disease...: How do we Approach and Manage it? Indian J Nephrol. 2017 May-Jun;27(3):167-71.

77 Power A, Chan K, Singh SK, Taube D, Duncan N. Appraising stroke risk in maintenance hemodialysis patients: a large single-center cohort study. Am J Kidney Dis. 2012 Feb; 59(2):249-57.

78 Seliger SL, Gillen DL, Longstreth WT Jr, Kestenbaum B, Stehman-Breen CO. Elevated risk of stroke among patients with end-stage renal disease. Kidney Int. 2003 Aug;64(2): 603-9.

79 Wang HH, Hung SY, Sung JM, Hung KY, Wang JD. Risk of stroke in long-term dialysis patients compared with the general population. Am J Kidney Dis. 2014 Apr;63(4):60411.

80 Toyoda K, Fujii K, Fujimi S, Kumai Y, Tsuchimochi $\mathrm{H}$, Ibayashi S, et al. Stroke in patients on maintenance hemodialysis: a 22-year single-center study. Am J Kidney Dis. 2005 Jun; 45(6):1058-66

81 Inrig JK. Intradialytic hypertension: a lessrecognized cardiovascular complication of hemodialysis. Am J Kidney Dis. 2010 Mar 55(3):580-9.

82 Power A, Davenport A, Brown EA, Duncan $\mathrm{N}$, Fan S. Stroke incidence and risk factors in peritoneal dialysis. J Am Soc Nephrol. 2012, 23:227A.

83 Mehrotra R, Chiu YW, Kalantar-Zadeh K, Bargman J, Vonesh E. Similar outcomes with hemodialysis and peritoneal dialysis in patients with end-stage renal disease. Arch Intern Med. 2011 Jan;171(2):110-8.

84 Chung S, Jeong HS, Choi DE, Song HJ, Lim YG, Ham JY, et al. The impact of hemodialysis and arteriovenous access flow on extracranial hemodynamic changes in end-stage renal disease patients. J Korean Med Sci. 2016 Aug 31(8):1239-45.

85 Regolisti G, Maggiore U, Cademartiri C, Cabassi A, Caiazza A, Tedeschi S, et al. Cerebral blood flow decreases during intermittent hemodialysis in patients with acute kidney injury, but not in patients with end-stage renal disease. Nephrol Dial Transplant. 2013 Jan; 28(1):79-85.

86 Hata R, Matsumoto M, Handa N, Terakawa H, Sugitani Y, Kamada T. Effects of hemodialysis on cerebral circulation evaluated by transcranial Doppler ultrasonography. Stroke. 1994 Feb;25(2):408-12. 
87 Stefanidis I, Bach R, Mertens PR, Liakopoulos V, Liapi G, Mann H, et al. Influence of hemodialysis on the mean blood flow velocity in the middle cerebral artery. Clin Nephrol. 2005 Aug;64(2):129-37.

88 Skinner H, Mackaness C, Bedforth N, Mahajan R. Cerebral haemodynamics in patients with chronic renal failure: effects of haemodialysis. Br J Anaesth. 2005 Feb;94(2):203-5.

89 Metry G, Spittle M, Rahmati S, Giller C, Giller A, Kaufman A, et al. Online monitoring of cerebral hemodynamics during hemodialysis. Am J Kidney Dis. 2002 Nov; 40(5):996-1004.

90 Robba C, Goffi A, Geeraerts T, Cardim D, Via G, Czosnyka M, et al. Brain ultrasonography: methodology, basic and advanced principles and clinical applications. A narrative review. Intensive Care Med. 2019 Jul; 45(7):913-27.

91 Findlay MD, Dawson J, Dickie DA, Forbes KP, McGlynn D, Quinn T, et al. Investigating the relationship between cerebral blood flow and cognitive function in hemodialysis patients. J Am Soc Nephrol. 2019 Jan;30(1): 147-58.

92 Mok V, Ding D, Fu J, Xiong Y, Chu WW, Wang D, et al. Transcranial Doppler ultrasound for screening cerebral small vessel disease: a community study. Stroke. 2012 Oct;43(10):2791-3.

93 Heliopoulos I, Artemis D, Vadikolias K, Tripsianis G, Piperidou C, Tsivgoulis G. Association of ultrasonographic parameters with subclinical white-matter hyperintensities in hypertensive patients. Cardiovasc Psychiatry Neurol. 2012;2012:616572.

94 Ghorbani A, Ahmadi MJ, Shemshaki H. The value of transcranial Doppler derived pulsatility index for diagnosing cerebral smallvessel disease. Adv Biomed Res. 2015 Feb; 4(1):54.

95 Postiglione A, Faccenda F, Gallotta G, Rubba $\mathrm{P}$, Federico $\mathrm{S}$. Changes in middle cerebral artery blood velocity in uremic patients after hemodialysis. Stroke. 1991 Dec;22(12): 1508-11.

96 McIntyre CW, Goldsmith DJ. Ischemic brain injury in hemodialysis patients: which is more dangerous, hypertension or intradialytic hypotension? Kidney Int. 2015 Jun; 87(6):1109-15.

97 Iyasere O, Okai D, Brown E. Cognitive function and advanced kidney disease: longitudinal trends and impact on decision-making. Clin Kidney J. 2017 Feb;10(1):89-94.

98 Purkayastha S, Sorond F. Transcranial Doppler ultrasound: technique and application. Semin Neurol. 2012 Sep;32(4):411-20.

99 Pirkle JL Jr, Comeau ME, Langefeld CD, Russell GB, Balderston SS, Freedman BI, et al. Effects of weight-based ultrafiltration rate limits on intradialytic hypotension in hemodialysis. Hemodial Int. 2018 Apr;22(2):270-8.
100 Marinoni M, Ginanneschi A, Forleo P, Amaducci L. Technical limits in transcranial Doppler recording: inadequate acoustic windows. Ultrasound Med Biol. 1997;23(8): 1275-7.

101 Kaczynski J, Home R, Shields K, Walters M, Whiteley W, Wardlaw J, et al. Reproducibility of Transcranial Doppler ultrasound in the middle cerebral artery. Cardiovasc Ultrasound. 2018 Sep;16(1):15.

102 Mariak Z, Krejza J, Swiercz M, Kordecki K, Lewko J. Accuracy of transcranial color Doppler ultrasonography in the diagnosis of middle cerebral artery spasm determined by receiver operating characteristic analysis. J Neurosurg. 2002 Feb;96(2):323-30.

103 Blanco P, Abdo-Cuza A. Transcranial Doppler ultrasound in neurocritical care. J Ultrasound. 2018 Mar;21(1):1-16.

104 Ninomiya T, Perkovic V, Gallagher M, Jardine M, Cass A, Arima H, et al.; PROGRESS Collaborative Group. Lower blood pressure and risk of recurrent stroke in patients with chronic kidney disease: PROGRESS trial. Kidney Int. 2008 Apr;73(8):963-70.

105 Weiner DE, Tighiouart H, Levey AS, Elsayed E, Griffith JL, Salem DN, et al. Lowest systolic blood pressure is associated with stroke in stages 3 to 4 chronic kidney disease. J Am Soc Nephrol. 2007 Mar;18(3):960-6.

106 Brooks JM, Chapman CG, Suneja M, Schroeder MC, Fravel MA, Schneider KM, et al. Use of Angiotensin-Converting Enzyme Inhibitors and Angiotensin Receptor Blockers for Geriatric Ischemic Stroke Patients: Are the Rates Right? J Am Heart Assoc. 2018 May;7(11):pii:e009137.

107 Carrero JJ, Trevisan M, Sood MM, Bárány P, $\mathrm{Xu} \mathrm{H}$, Evans $\mathrm{M}$, et al. Incident atrial fibrillation and the risk of stroke in adults with chronic kidney disease: the Stockholm CREAtinine Measurements (SCREAM) project. Clin J Am Soc Nephrol. 2018 Sep;13(9): 1314-20.

108 Wu VC, Wu PC, Wu CH, Huang TM, Chang $\mathrm{CH}$, Tsai PR, et al.; National Taiwan University Study Group on Acute Renal Failure (NSARF) Group. The impact of acute kidney injury on the long-term risk of stroke. J Am Heart Assoc. 2014 Jul;3(4):e000833.

109 Zheng D, Sato S, Arima H, Heeley E, Delcourt $C$, Cao $Y$, et al. INTERACT2 Investigators. Estimated GFR and the Effect of Intensive Blood Pressure Lowering After Acute Intracerebral Hemorrhage. Am J Kidney Dis. 2016 Jul;68(1):94-102.

110 Shima H, Mori T, Ooi M, Sonoda M, Shoji $\mathrm{T}$, Ishimura E, et al. Silent cerebral microbleeds and longitudinal risk of renal and cardiovascular events in patients with CKD. Clin J Am Soc Nephrol. 2016 Sep;11(9): 1557-65.
111 Shima H, Ishimura E, Naganuma T, Yamazaki T, Kobayashi I, Shidara K, et al. Cerebral microbleeds in predialysis patients with chronic kidney disease. Nephrol Dial Transplant. 2010 May;25(5):1554-9.

112 Kobayashi M, Hirawa N, Yatsu K, Kobayashi Y, Yamamoto Y, Saka S, et al. Relationship between silent brain infarction and chronic kidney disease. Nephrol Dial Transplant. 2009 Jan;24(1):201-7.

113 Shiao CC, Kan WC, Wang JJ, Lin YF, Chen $\mathrm{L}$, Chueh E, et al. Risk of incident non-valvular atrial fibrillation after dialysis-requiring acute kidney injury. J Clin Med. 2018 Aug;7(9):E248.

114 Kaw D, Malhotra D. Platelet dysfunction and end-stage renal disease. Semin Dial. 2006 Jul-Aug;19(4):317-22.

115 Balci C, Haftaci E, Kunt AT. Use of cerebral oxygen saturation and hemoglobin concentration to predict acute kidney injury after cardiac surgery. J Int Med Res. 2018 Mar; 46(3):1130-7.

116 Tsivgoulis G, Alexandrov AV. Ultrasound in Neurology. Continuum (Minneap Minn). 2016 Oct;22(5, Neuroimaging):1655-77.

117 Albayrak R, Degirmenci B, Acar M, Haktanir A, Colbay M, Yaman M. Doppler sonography evaluation of flow velocity and volume of the extracranial internal carotid and vertebral arteries in healthy adults. J Clin Ultrasound. 2007 Jan;35(1): 27-33.

118 Donahue J, Wintermark M. Perfusion CT and acute stroke imaging: foundations, applications, and literature review. J Neuroradiol. 2015 Feb;42(1):21-9.

119 Campbell BC, Christensen S, Levi CR, Desmond PM, Donnan GA, Davis SM, et al. Cerebral blood flow is the optimal CT perfusion parameter for assessing infarct core. Stroke. 2011 Dec;42(12):3435-40.

120 Zaharchuk G. Theoretical basis of hemodynamic MR imaging techniques to measure cerebral blood volume, cerebral blood flow, and permeability. AJNR Am J Neuroradiol. 2007 Nov-Dec;28(10):1850-8.

121 Thijs VN, Adami A, Neumann-Haefelin T, Moseley ME, Albers GW. Clinical and radiological correlates of reduced cerebral blood flow measured using magnetic resonance imaging. Arch Neurol. 2002 Feb; 59(2):233-8.

122 D'Andrea A, Conte M, Scarafile R, Riegler L, Cocchia R, Pezzullo E, et al. Transcranial Doppler ultrasound: physical principles and principal applications in neurocritical care unit. J Cardiovasc Echogr. 2016 Apr-Jun; 26(2):28-41.

123 Donnelly J, Budohoski KP, Smielewski P, Czosnyka M. Regulation of the cerebral circulation: bedside assessment and clinical implications. Crit Care. 2016 May;20(1): 129. 